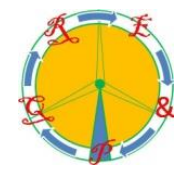

\title{
Modular buck-boost transformerless grid-tied inverter for low voltage solar panels
}

\author{
Hugo Nunes ${ }^{1}$, Nelson Pimenta ${ }^{1}$, Luís Fernandes ${ }^{1}$, Paulo Chaves ${ }^{1,2}$, J.M. Dores Costa ${ }^{2}$ \\ ${ }^{1}$ INOV - INESC Inovação \\ Rua Alves Redol, n 9, 1000-029 Lisbon, Portugal \\ Tel: +351213100444; Fax: +351213100445 \\ hugo.nunes@inov.pt; nelson.pimenta@inov.pt; luis.fernandes@inov.pt; paulo.chaves@inov.pt \\ ${ }^{2}$ Escola Superior Náutica I. D. Henrique \\ Marine Engineering Department, Oeiras, Portugal \\ Tel: +351214460010; Fax: +351214429546 \\ dores.costa@enautica.pt
}

\begin{abstract}
This paper deals with a transformerless AC module for low DC voltage output photovoltaic solar panels. The $\mathrm{DC}$ to AC converter was designed to be a single-phase grid-tied inverter, and is based on a buck-boost topology with currentmode control to shape the current and to adjust delivered power. The common ground node prevents voltage fluctuations and increases people's safety. Low power inverters tend to be less efficient than larger ones and are prone to higher harmonic distortion. To overcome these drawbacks, special care was taken in designing the power stage, and harmonic compensation was included in the control stage. The inverter has MPPT capability and operates with unity power factor. Inverter's operation is analysed, and some simulation results are presented. A $220 \mathrm{Wp}$ two-stage single-phase AC module prototype, with $240 \mathrm{~V}$ and $50 \mathrm{~Hz}$ sine-wave output, was build and connected to a low voltage photovoltaic solar panel. Experimental results for this plug-and-play converter are here presented.
\end{abstract}

\section{Key words}

Photovoltaic systems, AC module, transformerless buckboost, grid-tied inverter.

\section{Introduction}

Renewable energy sources are a growing slice in the world's energy, particularly photovoltaic solar (PV) systems as they use a free, abundant, and world spread energy resource. The increasing penetration of $\mathrm{PV}$ systems, and the decreasing prices in the PV market, can turn them in one of the most important power energy sources in the near future.

PV systems are used in centralized high-power plants, as power sources in smart-grid systems, or to supply locally small and disperse communities around the world. Governmental directives, oriented to reduce fossil fuel dependency and to promote low-carbon emissions, also encourage the installation of small-power grid-tied inverters. However, these inverters can represent up to $25 \%$ of the PV system cost [1] and continuing efforts are being done to reduce its cost, and to increase system's reliability. This work also focuses on inverter topologies and maximum power point trackers (MPPT) [2, 3].

PV solar panels and inverters may be used in different configurations, and the commonest solution is to associate single-phase or three-phase central inverters with PV panel strings [1]. PV panels are serial connected to obtain the high input DC voltage level needed by the single-stage inverter to connect the AC grid; and this way, strings can have DC voltages up to $500 \mathrm{~V}$, and higher $[4,5]$.

More recently, AC modules (or MIC - Module Integrated Converter) were proposed to integrate each PV panel in order to directly connect an AC grid without DC cables and related DC apparatus [6, 7]. AC modules can be massproduced at a reduced cost, and may include data acquisition and communication circuits to simplify maintenance works. To be packed together, PV panels and inverters must have equal lifetimes, and that is not the case yet. Small-power inverters tend to be less efficient than larger ones and a lot of work is still ongoing concerning inverter topologies and efficiency. Transformerless topologies are more interesting for integration, and since non-isolated inverters must have the PV panel frames earthed, this can be an advantage concerning people's safety [1].

This paper presents a plug-and-play AC module that was designed for a $220 \mathrm{Wp}$ PV panel with low DC voltage output. The principle of operation of a buck-boost transformerless inverter, and the control strategy, are described. Simulation and experimental results are included. 


\section{Integrated AC module}

AC modules, as shown in Fig. 1, consist of a microinverter integrated in a PV panel. These modules are proposed to increase the efficiency, to simplify the installation of PV systems with increased safety, and to reduce costs [6].

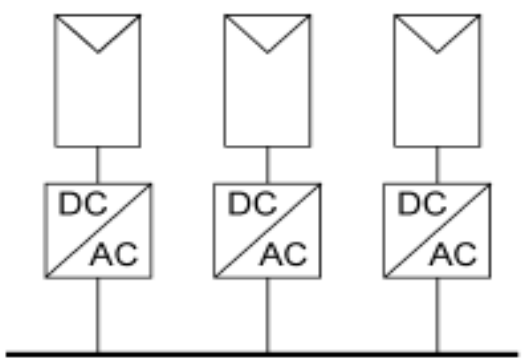

Fig. 1. Single-phase or three-phase array of AC modules.

Independent modules increase system reliability since most part of an AC array may continue to operate in the case of a single failure. And, since each module is individually optimized by his own MPPT, global efficiency is not affected by panels with different exposures.

MICs can use high-frequency transformers, or to be transformerless converters with added simplicity [8]. Transformerless topologies pose some challenges if they are used to interface a low output voltage PV panel (i.e. $12 \mathrm{~V}$ to $48 \mathrm{~V}$ ) with a rms $240 \mathrm{~V}$ AC grid. For instance, harmonic distortion tends to be more significant in low $\mathrm{AC}$ currents, and extreme duty-cycle values may pose practical problems to transistors drivers. Without the voltage boost provided by the transformer, a two-stage inverter may be a solution, despite the expected reduction of the global efficiency and cost increase. In Fig. 2 the transformerless converter uses a first stage boost converter, with MPPT, to increase the DC voltage to a level the inverter can generate the AC grid voltage.

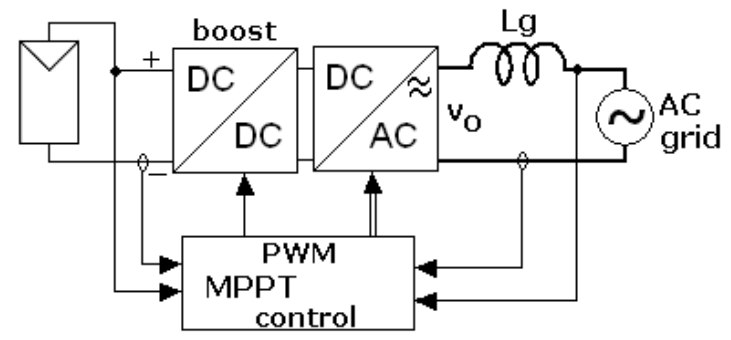

Fig. 2. AC module two-stage inverter.

Two-stage inverters usually use bulky capacitors to hold the DC bus voltage, and efforts are being done to develop single-stage inverters for compactness and cost reduction $[9,10]$. However, the smooth input current of boost and derived converters when in continuous current mode (CCM), and the MPPT control they provide are advantages to be considered. With higher input DC voltage the front boost converter is not needed and a single-stage transformerless inverter may be used with increased efficiency at a lower cost.

The DC-AC converter in Fig. 2 is often realized by singlephase H-bridge derived inverters but several others are referred in literature [11]. In the following we will consider a transformerless buck-boot based inverter with a common earthed node.

\section{Buck-boost inverter}

The buck-boost converter in Fig. 3 is a well-known basic topology of a DC-DC converter [12] that realizes an energy transfer between two voltage sources through a current source formed by the inductor. When $S$ is on $(S$ on) the energy flowing from the input source is stored in the inductor and released to the output when $S$ is off. The power transferred may be controlled by shaping inductor current, $i_{L}$.

In the following, ideal switches are assumed, and voltage and current ripple are neglected. When $S$ is on and $D$ is off $i_{L}$ increases, and when $S$ is off and $D$ is on $i_{L}$ decreases, both in an approximately linear fashion, since $v_{1}$ and $v_{O}$ do not vary significantly during one switching period $T_{s}=1 / f_{s}$.

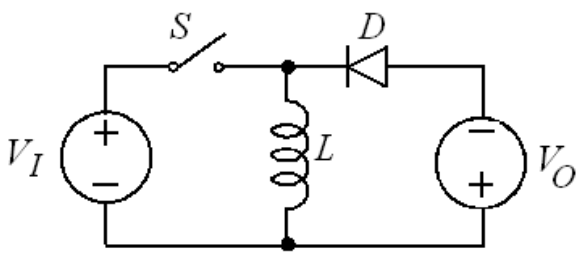

a)

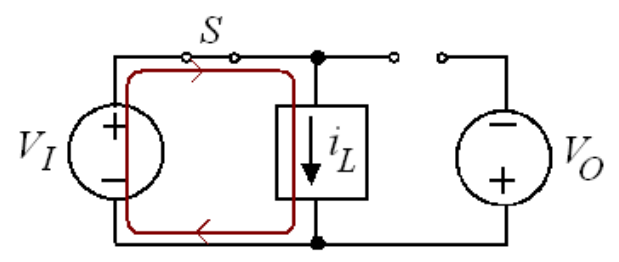

(b)

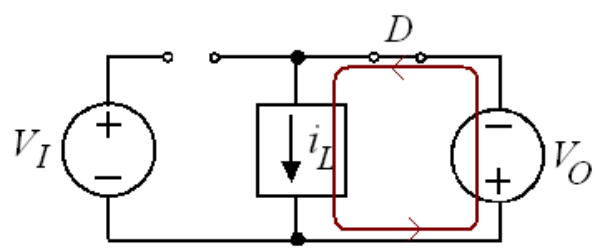

(c)

Fig. 3. Buck-boost converter; (a) basic topology; (b) stage 1 ( $S$ on); (c) stage 2 ( $D$ on).

By admitting CCM, if $v_{O}(t)=\left|V_{O} \sin (2 \pi f t)\right|$ and $f_{s}>>f$, then the duty-cycle may be given by

$$
d(t)=\frac{m(t)}{1+m(t)}
$$

where

$$
m(t)=\frac{V_{O}|\sin (\omega t)|}{V_{I}}=k|\sin (\omega t)|
$$


Duty-cycle (1) is represented in Fig. 4 for different voltage ratios $k=V_{O} / V_{I}$. It is clear that $d(t)$ starts to increase as faster the lower $V_{I}$ is. This "saturation" of $d(t)$ causes the energy be transferred to the output during phase 2 in a short time period, most of the time. As a consequence, $v_{O}(t)$ will present some "saturation" and it is expected that harmonic distortion increases with $k$. Thus, some filtering may be needed to meet standards.

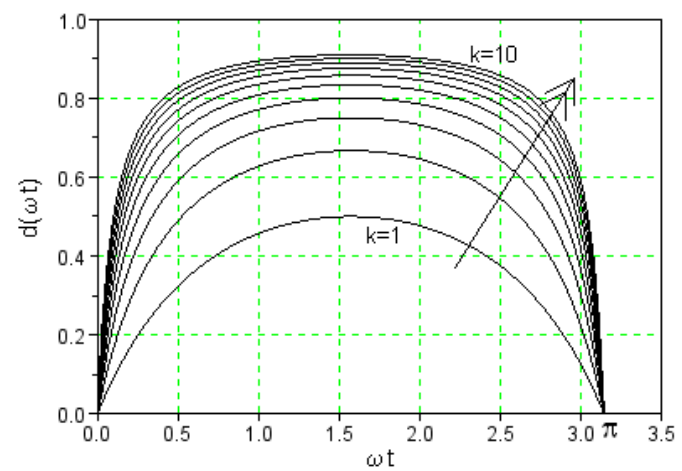

Fig.4. Duty-cycle for $1<k=V_{O} / V_{I}<10$.

In Fig. 3, for $v_{O}(t)=\left|V_{O} \sin (2 \pi f t)\right|$ and considering a resistive load, and neglecting the high-frequency ripple, the inductor current has a sampled wave given by

$$
i_{L}\left(t_{n}\right)=I_{O} \frac{\left|\sin \left(\omega t_{n}\right)\right|}{1-d\left(t_{n}\right)}
$$

where $t_{n}$ means the time at the $n^{\text {th }}$ switching cycle.

Normalized values of (3) are represented in Fig. 5 for different values of $k$. Current $i_{L}$ is non negative and can have a high peak value, depending on the available power. Power transferred from the DC source to the AC source can be controlled by adjusting the peak value of $i_{L}$ using a current mode control (CMC) law [1].

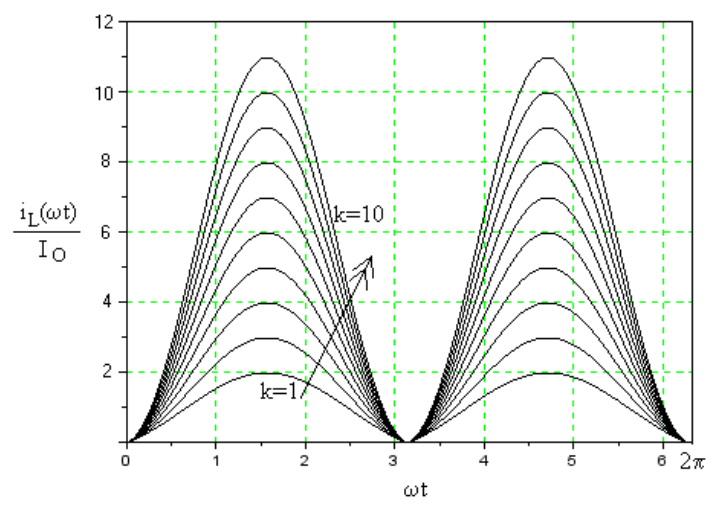

Fig.5. Normalized $i_{L}(t)$ for $1<k=V_{O} / V_{I}<10$.

The inverter in Fig. 6 includes a non-inverting buck-boost converter [13] to generate $v_{O}(t) \geq 0$, with paths (and stages) shown in Fig. 7(a). Fig. 7(b) shows paths (and stages) of a conventional buck-boost converter if $v_{O}(t)<0$. The inverter in Fig. 6 is also known as flying inductor, or Karschny topology $[1,8,10]$. It may work as a buck converter when $V_{I} \geq\left|v_{O}(t)\right|$, or as a boost converter when $V_{I}<\left|v_{O}(t)\right|$. References of the flying inductor topology known in literature are insufficient to design the application for a low voltage PV panel.

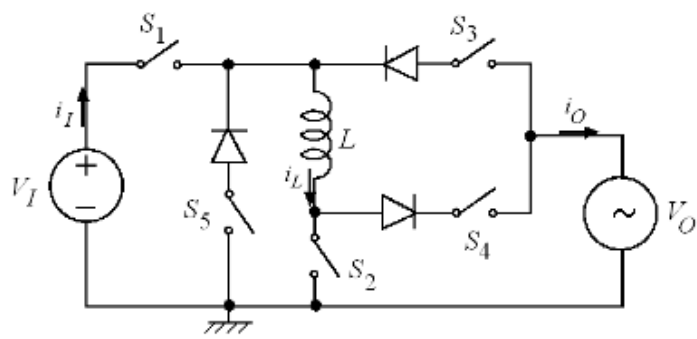

Fig. 6. Buck-boost based DC-AC converter.

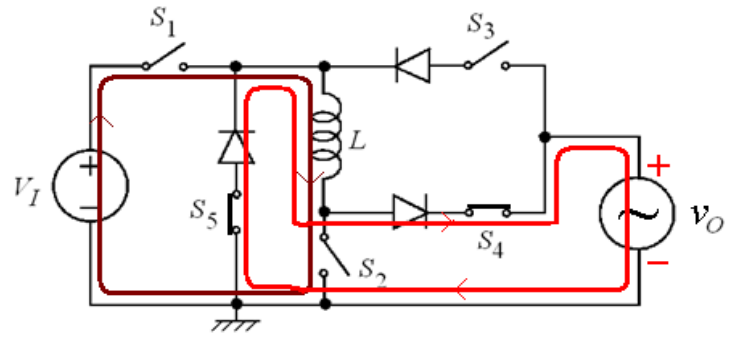

(a)

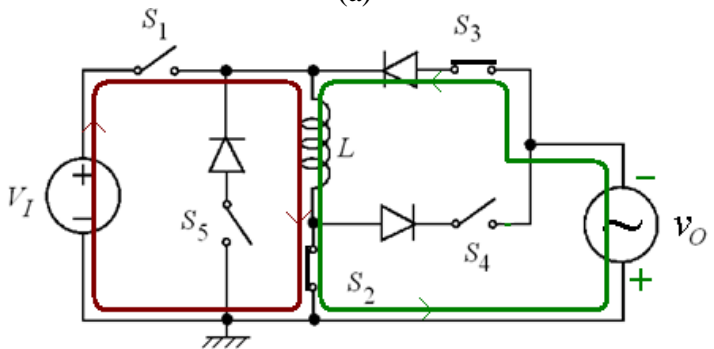

(b)

Fig. 7. Buck-boost based inverter and current paths: (a) for $v_{O} \geq 0$; (b) for $v_{O}<0$.

In this paper the inverter works as a buck-boost converter with CMC with unidirectional switches being controlled as in table 1; $S_{1}$ and $S_{2}$ are high-frequency (HF) switches to obtain buck-boost stages in CCM, and the others are low-frequency switches (with the grid frequency, $f$ ).

Table 1. State of the inverter switches.

\begin{tabular}{|c|c|c|c|c|c|}
\cline { 2 - 6 } \multicolumn{1}{c|}{} & $S_{1}$ & $S_{2}$ & $S_{3} D_{3}$ & $S_{4} D_{4}$ & $S_{5} D_{5}$ \\
\hline$V_{O} \geq 0$ & $\mathrm{HF}$ & $\mathrm{HF}$ & $\mathrm{OFF}$ & $\mathrm{ON}$ & $\mathrm{ON}$ \\
\hline$V_{O}<0$ & $\mathrm{HF}$ & $\mathrm{ON}$ & $\mathrm{ON}$ & $\mathrm{OFF}$ & $\mathrm{OFF}$ \\
\hline
\end{tabular}

Let $i_{O}$ in Fig. 6 to have a low-frequency grid component $i_{O L}(t)=I_{O} \sin (2 \pi f t+\varphi)$ with $f<<f_{s}$. From (3), the sampled value of $i_{L}$ at the $n^{\text {th }}$ switching cycle can be given by

$$
i_{L}\left(t_{n}\right)=\frac{I_{O}\left|\sin \left(\omega t_{n}+\varphi\right)\right|}{1-d\left(t_{n}\right)}
$$

From (1) and (2) the sampled duty-cycle is

$$
d\left(t_{n}\right)=\frac{m\left(t_{n}\right)}{1+m\left(t_{n}\right)}=\frac{V_{O}\left|\sin \left(\omega t_{n}\right)\right|}{V_{I}+V_{O}\left|\sin \left(\omega t_{n}\right)\right|}
$$


By replacing (5) in (4) and rearrange it, sampled values of the inductor current are obtained:

$i_{L}\left(t_{n}\right)=I_{O}\left|\sin \left(\omega t_{n}+\varphi\right)\right|+\frac{I_{O} V_{O}}{2 V_{I}}\left|\cos \left(2 \omega t_{n}+\varphi\right)-\cos (\varphi)\right|$

Dividing (6) by $I_{O}$ Fig. 5 is obtained. The DC component in (6) is related with the power taken from the input source with constant $V_{I}$; AC components are related with the power injected in the output source with the sinusoidal voltage $v_{O}$. For an ideal converter the input power, $P_{I}$, is given by (7); with $\mathrm{PF}=1(\varphi=0),(6)$ reduces to $(8)$ where $I_{I}$ is the mean value of the current in $S_{1}$ (Fig. 5).

$$
\begin{gathered}
P_{I}=V_{I} I_{I}=\frac{V_{O} I_{O}}{2} \\
i_{L}\left(t_{n}\right)=I_{O}\left|\sin \left(\omega t_{n}\right)\right|+I_{I}\left|\cos \left(2 \omega t_{n}\right)-1\right|
\end{gathered}
$$

The inductor must be designed to support the peak value of (6), imposed by the MPPT, with reduced losses and without going into saturation. Care must be taken for the minimum value of $V_{I}$ because the peak of $i_{L}$ in (6) may be higher than $I_{S C}$ of the PV panel. For a lower $L$ discontinuous current conduction mode occurs, mainly when $v_{O}$ is near zero and for small values of the instantaneous power. Large values of $L$ can be used to reduce harmonic distortion, but it increases the volume of the core and iron losses.

\section{Buck-boost AC module prototype}

The prototype of the buck-boost transformerless grid-tied inverter, with a common earthed terminal, is represented in Fig. 8. Switching stages are those derived from Fig. 7. The inverter was designed to connect one $225 \mathrm{Wp} \mathrm{PV}$ panel, with a MPP output voltage of $29 \mathrm{~V}$ and short-circuit current $I_{S C}=8.33 \mathrm{~A}$, to the European AC grid $(230 \mathrm{~V}$, $50 \mathrm{~Hz}$ ). Initially, the goal was to use a single-stage transformerless converter. However, with $k_{P} \geq 10$, to have $i_{L}<I_{S C}$ it is found from (8) that it must be $V_{I}>70 \mathrm{~V}$. Consequently, we decided to add a boost converter and to build the two-stage inverter in Fig. 9.

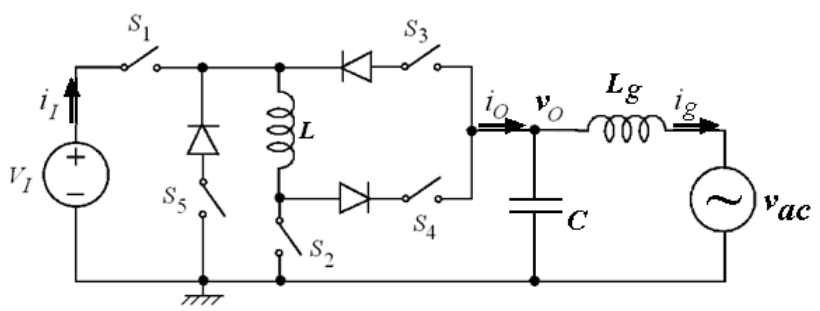

Fig. 8. Single-phase buck-boost grid-tied inverter.

The boost converter maintains $V_{D C}=140 \mathrm{~V}$ and is in charge of the MPPT, which is held by a hill-climbing algorithm [3] implemented in a standard low-cost 16 bit microcontroller. A mixed digital-analogue PI controller produces a reference signal to shape $i_{L}$ considering the available power and an harmonic compensation. A data acquisition and communication system was also included to monitor the prototype and to record relevant data.

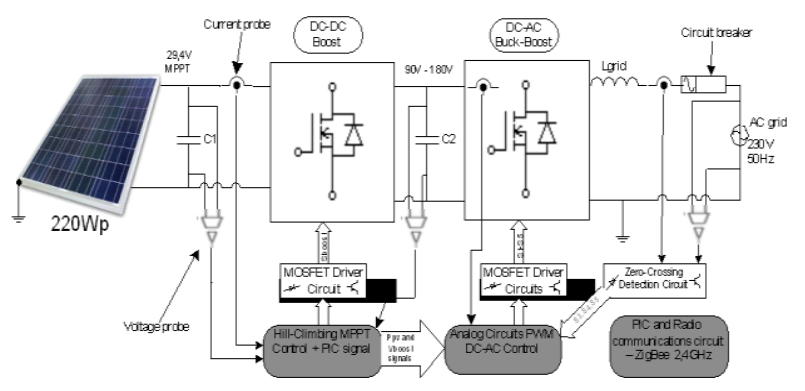

Fig. 9. The prototype of the two-stage grid-tied inverter.

Communications use a $2.4 \mathrm{GHz}$ wireless radio system based on the 802.15.4 standard. The power delivered and the converter's efficiency can be obtained in real time.

Capacitor $C$ in Fig. 8 is needed to interconnect the two inductors. The current source performed by inductor $L$ will charge $C$, when $S_{3}$ or $S_{4}$ are on and $S_{1}$ is off, with the energy that will be transferred to the grid when $S_{1}$ is on.

High-frequency ripple of $v_{O}(t)$ influences the THD of $i_{g}$, and $L_{g}$ can be designed to reduce it. Being $\Delta i_{g}$ and $\Delta v_{O}$ current and voltage ripple, respectively, $L_{g}$ and $C$ can be obtained from (9) and (10),

$$
\begin{gathered}
L g \leq \frac{V_{O}\left(1-d_{\max }\right)}{\Delta i_{g} f_{s}} \\
C \geq \frac{P_{P} d_{\max }}{\Delta v_{O} f_{s} V_{O}}
\end{gathered}
$$

where $P_{P}$ is the expected maximum power to be delivered from the PV module. To limit the THD of $i_{g}$, the resonant frequency of $L_{g}$ and $C$ must be at least one decade below $f_{s}$.

Fig. 10 shows $i_{L}$ and $i_{g}$ resulting from a simulation run with PSIM software (from Powersimtech) of the two-stage converter in Fig. 9 for $110 \mathrm{~W}$ output power $(50 \%$ of peak power). Results show a good agreement with expected values in Fig. 5.

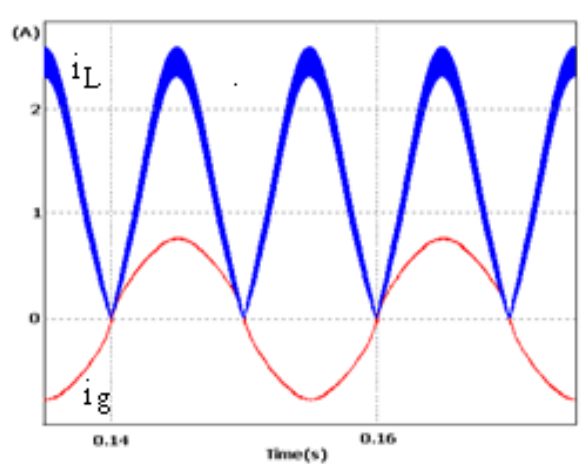

Fig. 10. Simulation results of $i_{L}$ and $i_{g}$. 


\section{Experimental results}

To verify the validity of the above analysis a $220 \mathrm{Wp}$ prototype of the circuit in Fig. 9 was designed, built and tested. Considering minimum values of $10 \mathrm{~W}$ and $d \geq 10 \%$, and current and voltage ripple to be less than $10 \%$, the following parameters were obtained: $L=1 \mathrm{mH}, C=200 \mathrm{nF}$, $L_{g}=1 \mathrm{mH}$. It was verified by simulation that the MPPT control is able to maintain $90 \mathrm{~V} \leq V_{I} \leq 140 \mathrm{~V}$, and that the peak of $i_{L}$ was less than 6A. The boost stage is no needed if the PV module has $V_{I} \geq 90 \mathrm{~V}$; this assumption could be verified experimentally.

Fig. 11 shows experimental results of the grid voltage and current for $35 \mathrm{~W}$ and $110 \mathrm{~W}$ output power. The euroefficiency [5] obtained for the two-stage converter was $90 \%$ and the one obtained for the buck-boost converter is $94 \%$. Power factor is close to unity.

Fig. 12 shows the low-frequency amplitude spectrum (FFT) of the grid-current, $i_{g}$, the THD of which, following IEC61000-3-2-A standard [6], is less than 5\%. Fig. 13 shows the allowable PV power, $P_{P V}$, and the power effectively delivered to the grid, $P_{\text {OUT, }}$, during part of the day. Data was collected in real time, by the data acquisition circuit, and wireless transmitted for lab monitoring. The efficient performance of the MPPT and control circuits can be observed. The resulting gross efficiency is close to $95 \%$.

A general view of the prototype is shown in Fig. 14. The inverter can be fixed on the rear of the solar panel and easily plugged to the mains.

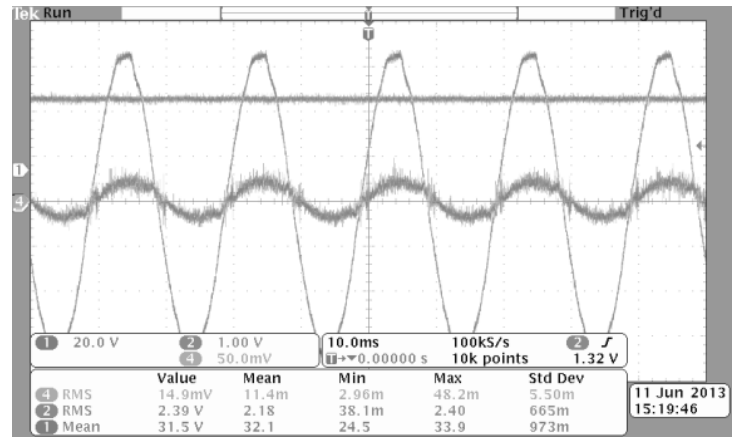

(a) $35 \mathrm{~W}$

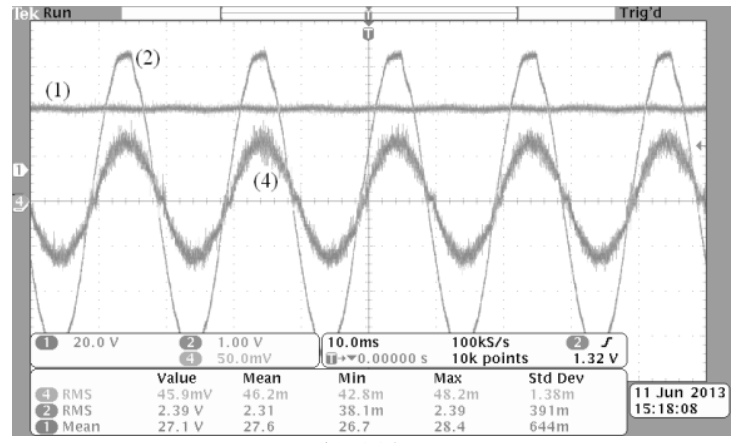

(b) $110 \mathrm{~W}$

Fig.11. Experimental results; (1) PV panel voltage; (2) $v_{a c}$; (4) $i_{g}$;

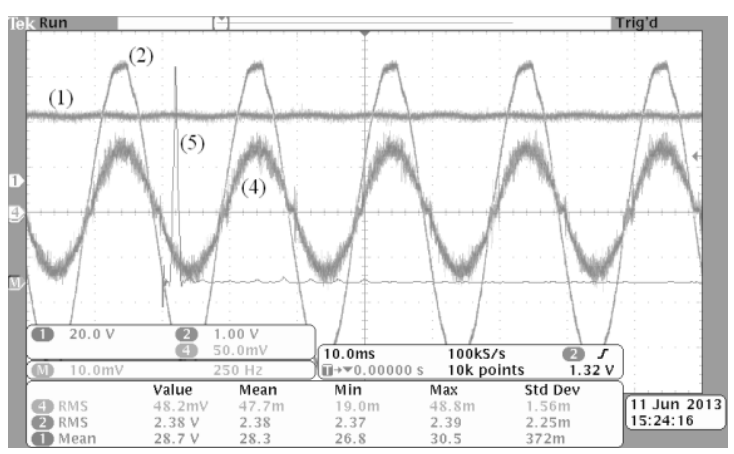

Fig. 12. Experimental results, 110W; (1) PV panel voltage; (4) current $i_{g}$; (5) amplitude spectrum of $i_{g}$.

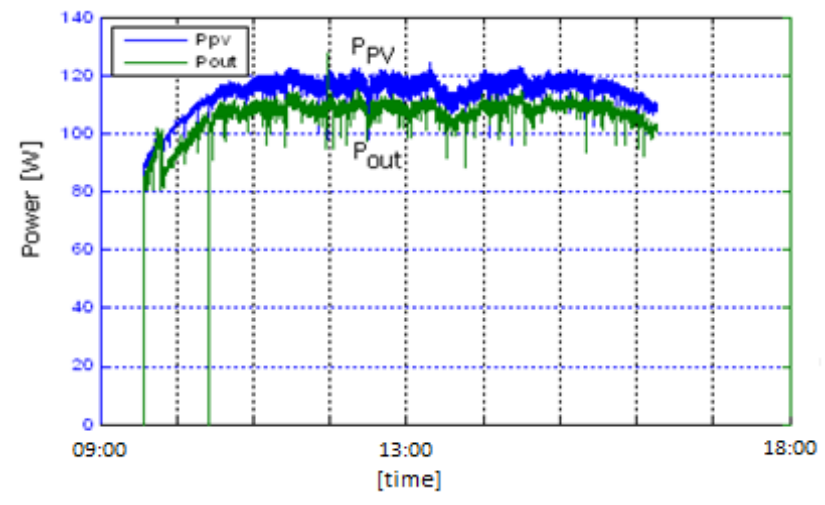

Fig. 13. Input and output power.

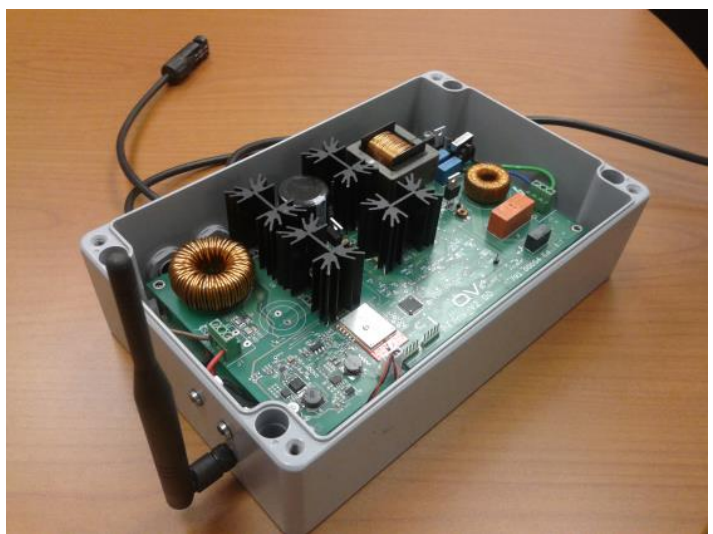

Fig. 14. Prototype general view.

\section{Conclusions}

Although less efficient, low voltage and low power inverters can improve efficiency and reliability of the global PV system with a reduced cost. Bearing this in mind, a buck-boost transformerless inverter, with CCM, was developed to work as grid-tied micro-inverter with an usual low voltage PV solar panel.

The inverter analysis, simulation and experimental results of a prototype circuit were presented. These results show a good agreement with the expected ones, and show that, with the proper control strategy, buck-boost converters 
with current mode control can be used to inject power in the grid with good efficiency and reduced THD.

Although the output stage of the buck-boost converter has no current filter, experimental results indicates that the harmonic cancellation circuit can substantially reduce the THD, even for low peak amplitude currents.

With further optimization of some of the electronic components, our prototype may accomplish the benchmark for domestic PV systems referred in [2].

\section{References}

[1] Fritz Schimpf, Lars E. Noruml, "Grid connected Converters for Photovoltaic, State of the Art, Ideas for Improvement of Transformerless Inverters", NORPIE/2008, Nordic Workshop on Power and Industrial Electronics, June 9-11, 2008, pp.1-5.

[2] Alan Goodrich, Ted James, Michael Woodhouse, "Residential, Commercial, and Utility-Scale Photovoltaic (PV) System Prices in the United States: Current Drivers and CostReduction Opportunities", NREL Technical Report/TP-6A2053347, February 2012.

[3] V. Salas, E. Olias, A. Barrado, A. Lazaro, "Review of the maximum power point tracking algorithms for stand-alone photovoltaic systems", Solar Energy Materials \& Solar Cells 90 (2006), pp. 1555-1578.

[4] R. Attanasio, M. Cacciato, F. Gennaro, G. Scarcella, "Review on Single-phase PV Inverters for Grid-connected Applications", 4th IASME/WSEAS, International Conference on Energy, Environment, Ecosystems and Sustainable Development (EEESD'08), Algarve, Portugal, June 11-13, 2008.

[5] O.Stalter, D. Kranzer, S. Rogalla and B. Burger, "Advanced Solar Power Electronics", ISPSD2010, 22nd International Symposium on Power Semiconductor Devices \& ICs, Hiroshima, 2010.
[6] Soeren Baekhoej Kjaer, John K. Pedersen, and Frede Blaabjerg, "A Review of Single-Phase Grid-Connected Inverters for Photovoltaic Modules", IEEE Trans. on Industry Applications, vol. 41, no. 5, September/October 2005, pp 12921306.

[7] Quan Li, Peter Wolfs, "A Review of the Single Phase Photovoltaic Module Integrated Converter Topologies With Three Different DC Link Configurations", IEEE Trans. on Power Electronics, vol. 23, no. 3, May 2008, pp. 1320-1333.

[8] Samuel Vasconcelos Araújo, Peter Zacharias, Regine Mallwitz, "Highly Efficient Single-Phase Transformerless Inverters for Grid-Connected Photovoltaic Systems", IEEE Trans. on Industrial Electronics, vol. 57, no. 9, September 2010, pp. 3118-3128.

[9] Ribeiro, H., Silva, F., Pinto, S., Borges, B., "Single stage inverter for PV applications with One Cycle Sampling technique in the MPPT algorithm", Industrial Electronics, Nov. 2009. IECON '09. 35th Annual Conference of IEEE.

[10] D. Petreus, S. Daraban, I. Ciocan, T. Patarau, C. Morel, "Single-Stage Low Cost Grid Connected Inverter in Photovoltaic Energy Applications", 15th International Power Electronics and Motion Control Conf. EPE-PEMC 2012 ECCE Europe, Novi Sad, Serbia, pp. 1-6.

[11] Yaosuo Xue, Liuchen Chang, Søren Bækhøj Kjær, Josep Bordonau, and Toshihisa Shimizu, Topologies of Single-Phase Inverters for Small Distributed Power Generators: An Overview, IEEE Trans. on Power Electronics, vol. 19, no. 5, September 2004 pp. 1305-1314

[12] W. N. Mohan, T. Undeland, and W. P. Robbins, Power Electronics: Converters, Applications, and Design. New York: Wiley, 2003.

[13] Sahu, B.; Rincon-Mora, G.A., "A low voltage, dynamic, noninverting, synchronous buck-boost converter for portable application", IEEE Trans. Power Electronics 2004, pp. 443-452. 